\title{
Humor gráfico e resistência cultural na última ditadura militar argentina
}

Ana Marília Carneiro ${ }^{1}$

Resenha de: BURKART, Mara. De Satiricón a Hum®: risa, cultura y política en los años setenta. Buenos Aires: Miño y Dávila Editores, 2017.

Resenha recebida em: $21 / 11 / 2017$

Resenha aprovada em: 07/08/2018

O golpe militar de março de 1976 inaugura um dos períodos mais violentos e repressivos da história argentina, consistindo em um dos temas centrais nos ciclos de produção e reflexão intelectuais sobre as experiências ditatoriais latino-americanas. De Satiricón a Hum®: risa, cultura y política en los años setenta, livro de Mara Burkart, publicado no ano de 2017, dedica-se justamente a abordar um tema relevante e ainda pouco visitado na produção historiográfica argentina envolvendo o período ditatorial: as relações entre imprensa gráfica de humor, cultura e política a partir da perspectiva de resistência cultural.

Com a queda da última ditadura militar argentina em 1983 e em meio ao clima de transição democrática, as análises produzidas no calor dos acontecimentos sobre o passado recente foram provenientes sobretudo dos campos da sociologia e da ciência política, tendo os historiadores se mantido inicialmente distantes desse processo. Somente em anos posteriores, devido ao processo de afirmação da ditadura militar como problema histórico e o desenvolvimento do campo e dos aportes trazidos pela história recente é que foi possível perceber um avanço mais consistente na produção que situa a ditadura militar como objeto de investigação e reflexão a partir de uma perspectiva histórica ${ }^{2}$.

\footnotetext{
${ }^{1}$ Doutoranda em História, Universidade Federal de Minas Gerais (UFMG), Brasil. Título provisório da tese em andamento: "A censura cinematográfica nas ditaduras militares brasileira (1964-1988) e argentina (1966-1983)”, Bolsista CAPES. E-mail: anammc@gmail.com

${ }^{2}$ Um panorama da produção acadêmica e uma análise mais detalhada sobre a configuração da ditadura militar como objeto de investigação no campo historiográfico argentino podem ser consultados no artigo de Gabriela Águila: Cf. ÁGUILA, Gabriela. La dictadura militar argentina: interpretaciones, problemas e debates. Páginas Revista digital de la escuela de historia, Rosario, v. 1, n. 1, 2008. Disponível em: $\langle\underline{h t t p}: / /$ revistapaginas.unr.edu.ar/index.php/RevPaginas/article/view/148/148 > Acesso em: 20 set. 2017.
}

\section{GANPHLAC}


A partir dos anos 2000, percebe-se um movimento profícuo de novos questionamentos e o aprofundamento das reflexões teóricos-metodológicas sobre a ditadura militar, gerando uma pluralidade de estudos com temáticas renovadas ou pouco visitadas pela historiografia. A formação ideológica das forças armadas, as relações cívicomilitares estabelecidas durante a vigência do regime, a reestruturação do arcabouço militar pós 1983, as resistências e acomodações na sociedade civil, são alguns dos temas presentes na produção histórica recente na Argentina — impulsionados também pela abertura de arquivos e acessibilidade de novos acervos e documentos sobre a repressão.

O estudo de Mara Burkart — que não é historiadora, mas sim socióloga de formação - é um exemplo resultante desse processo de renovação historiográfica em curso nos últimos anos na Argentina envolvendo o desenvolvimento de um conjunto de pesquisas de caráter histórico também no campo das ciências sociais. Valendo-se de métodos e abordagens historiográficos, seu trabalho se insere em uma linha de investigação recente que se dedica a analisar as estratégias de luta, resistências e oposições culturais ao regime ditatorial ${ }^{3}$.

A proposta central da obra De Satiricón a Hum®: risa, cultura y política en los años setenta é perceber, a partir do exame de revistas de humor gráfico produzidas nas décadas de 1970 e 1980, as condições que tornaram possíveis a emergência e consolidação de um espaço de resistência cultural em meio a um ambiente marcado pela censura, autoritarismo e repressão da última ditadura militar argentina.

O estudo de Burkart se insere na interseção entre a história cultural e a história política, concebendo a cultura como um campo conflituoso, um espaço privilegiado de circulação e produção de valores, visões de mundo, representações e imaginários em disputa no cenário político. A inspiração teórico-metodológica proveniente dos aportes da história cultural é explícita: as representações e discursos em disputa no jogo político não são animados por textos e imagens meramente estáticos e abstratos, mas produzem

\footnotetext{
3 Além de diversas teses e dissertações oriundas das investigações de Programas de Pós-graduação, algumas das obras mais relevantes que tratam da relação entre cultura e política durante a ditadura militar argentina são: BUCH, Esteban. Música, dictadura, resistencia: la Orquesta de París en Buenos Aires. Buenos Aires: Fondo de Cultura Económica, 2016; COSSE, Isabela. Mafalda: história social e política. Buenos Aires: Fondo de Cultura Economica, 2014; LEVÍN, Florencia. Humor político en tiempos de represión. Clarín, 1973-1983. Buenos Aires: Siglo XXI, 2013; SLIPAK, Daniela. Las revistas montoneras: como la organización construyó su identidad através de sus publicaciones. Buenos Aires: Siglo XXI, 2015; VERZERO, Lorena. Teatro militante: radicalización artística y política en los años 70 . Buenos Aires: Ed. Biblos, 2013.
}

\section{GANPHLAC}


sentidos, orientam e engendram práticas e relações no campo social. Nesse sentido, as revistas de humor gráfico são compreendidas como elementos pertencentes ao campo midiático e cultural que adquiriu contornos específicos quando as forças armadas tomam o poder em 1976. Para além de um produto cultural, as revistas são tomadas como armas de resistência e o humor gráfico como uma estratégia de luta, ora mais metafórica, ora mais literal, a depender das condições de dizibilidade vigentes em determinada conjuntura sócio-histórica.

Sem dúvida, o golpe de 24 de março de 1976 significou um momento de inflexão na ordem democrática argentina, mas é importante assinalar que a repressão e o autoritarismo cujo clímax se deu no pós-1976 está inscrita em práticas que estiveram em marcha nos anos prévios ao período ditatorial. Uma quantidade expressiva de estudos definiu a periodização de suas análises da ditadura militar somente a partir de uma perspectiva de ruptura, deixando de lado a dinâmica complexa que envolve avanços, recuos e continuidades presentes no desenrolar do processo histórico. A preocupação em perceber essas dimensões está presente no trabalho de Mara Burkart: ao realizar uma análise diacrônica das condições sociais de produção cultural, coloca em evidência as mudanças e continuidades no campo da indústria de revistas de humor gráfico que se desenrolam ao longo de toda a década de 1970. Sob esse aspecto, a obra de Burkart se alinha a uma tendência de novas investigações que mudam uma perspectiva teórica de periodização mais tradicional e estendem temporalmente os seus períodos de estudo. Ao tomar a década de 1970 como um todo e não somente os anos da ditadura militar, a análise se potencializa e enriquece com uma percepção mais acurada sobre as [des]continuidades e lógicas de funcionamento sociais e políticas que não estão inscritas somente em uma periodização ${ }^{4}$.

O primeiro capítulo do livro De Satiticón a Hum ${ }^{\circledR}$ destaca o início dos anos de 1970 como um momento de expansão do mercado de produtos culturais marcado pela

\footnotetext{
${ }^{4}$ Nos últimos anos, alguns estudos ampliaram a periodização tradicional dos anos de 1976-1983 e investiram na análise das décadas de 1960 e início dos anos 1970: MANZANO, Valeria. contra toda forma de opressor: sexo politica y classes medias juvenil en las revistas de humor de los primeiros 70. Sociohistorica. Cuadernos del CIHS, n. 29, 2012, p. 9-34; FRANCO, Marina. Un enemigo para la nación: ordem interno, violência y "subversión", 1973-1976. Buenos Aires: Fondo de cultura Económica, 2012. Essa perspectiva também é teorizada e adotada em diversos artigos dos dois volumes da coletânea Problemas de historia reciente del Cono sur. Cf. BOHOSLAVSKY, Ernesto; FRANCO, Marina., IGLESIAS, Mariana; LVOVICH, Daniel (Orgs.). Problemas de historia reciente del Cono sur. V. 1 e 2. Buenos Aires: UNGS/Prometeo, 2010.
}

\section{GANPHLAC}


ascensão da indústria cultural de massa. Nesse cenário, a autora situa o surgimento de diversas publicações (Hortensia [1971], Satiricón[1972], Chaupinela[1974], Mengano[1974]) voltadas ao público jovem de classe média urbano incorporando em suas páginas o clima de revolução cultural e sexual dos anos 60. A crise da ditadura militar instaurada em 1966 e a consequente distensão da censura no início da década de 1970 viabilizaram um impulso de politização da cultura e de modernização dos meios de comunicação, criando um ambiente de renovação do periodismo gráfico e de novos espaços de sociabilidade. Satiricón surge como um ponto de partida na análise da autora, uma experiência inovadora no gênero, marcando o retorno da sátira política e a revitalização do humor irreverente no plano dos costumes nas publicações da época: "su comicidade expresó una posición liberal y moderna com respeito a las costumares y los valores culturales; y antipopular, antiperonista y antioficialista en materia política" (BURKART, 2017, p. 364).

O advento do golpe de 1976 e o discurso militar de "restauração da ordem" interromperam a publicação de Satiricón, uma revista vinculada ao ambiente de efervescência e contestação social do início dos anos de 1970. O período que se estende entre os anos de 1974 e 1978, analisado no segundo capítulo do livro, é marcado pelo progressivo fechamento do espaço público e a consequente retração das produções culturais e da imprensa humorística. Essa situação começa a se reverter gradualmente em meados de 1978, com o surgimento da revista Hum®.

Mara Burkart situa Satiricón como um antecedente de Hum®, um evento que permitiu o acúmulo de experiências e a gestação de condições de produção necessários para a emergência de novos projetos contestatórios no campo cultural. No entanto, diferentemente de Satiricón, Hum ${ }^{\circledR}$ afasta-se da frivolidade que havia caracterizado Satiricón e assume uma postura mais combativa perante o regime vigente: "el uso que hizo de lo cómico le permitió tomar distancia, cuestionar y confrontar al desvelar las prácticas, expectativas, valores y significados que los militares y sus aliados estaban imponiendo de modo autoritário e violento" (BURKART, 2017, p. 365).

Um dos méritos da obra de Burkart é conseguir explorar de forma competente a trajetória de $H u m ®$ analisando não apenas o projeto editorial da revista e sua recepção pelo público, mas também explicando de que maneira uma experiência periodística de

\section{GANPHLAC}


humor gráfico conseguiu nascer — e sobreviver - apesar da censura e das arbitrariedades do regime autoritário.

Qual a linguagem adotada e através de quais imagens era representada a repressão perpetrada pelo Estado nessas revistas? Como o cômico foi mobilizado com fins políticos? De que forma o público percebeu a violência e o autoritarismo representado em charges, sátiras e caricaturas? A análise empreendida pela autora recorre à história dos livros e da leitura, à história intelectual e à sociologia da cultura para responder a tais questões: ao longo de todo o texto estão presentes considerações sobre os aspectos de construção das revistas, as condições técnicas de sua produção e circulação, os espaços de sociabilidade pelos quais transitaram a equipe de redação assim como as relações entre texto e imagem, as relações do leitor com o suporte e a materialidade das revistas. Importante ressaltar a cuidadosa leitura das imagens gráficas realizadas pela autora: é uma tarefa desafiadora interpretar as representações, os signos, as mensagens presentes nas imagens veiculadas na época, assim como as possibilidades de apropriação pelo leitor. Ou mesmo como essas imagens sequer chegavam às mãos dos leitores, já que o controle exercido pelo Estado sobre as publicações durante a ditadura militar configurava uma prática institucionalizada, e muitos exemplares tratados em De Satiricón a Hum ${ }^{\circledR}$ foram censurados tendo sua circulação proibida.

Como ressalta a autora, em meados da década de 1970, o processo de fechamento do espaço público limitou a autonomia e o potencial crítico das publicações de humor gráfico, afinal, as alterações estrutural e subjetiva trazida pelos militares no poder significaram uma grande crise no campo cultural e midiático. Uma das linhas de investigação do livro de Mara Burkart é analisar os momentos de distensão do governo militar e as estratégias de luta visando à gradual retomada do espaço público pelas produções culturais.

Nos dois últimos capítulos, última parte do livro, Mara Burkart foca justamente no período entre 1981 e 1983, quando a ditadura militar caminhava rumos aos seus estertores. Em tal ponto do texto, desdobra-se uma das linhas de força do argumento da autora: situar a experiência de Hum® como uma manifestação de oposição que se desenvolveu no âmbito da cultura de massa, distanciando-se assim de uma interpretação dicotômica reducionista comum nas produções das décadas de 1980 e 1990, que vincu-

\section{GANPHLAC}


lava as publicações alternativas ou undergrounds a expressões de resistência e as publicações da grande imprensa como cúmplices ou colaboradores do regime.

Apesar da atmosfera de tensão acirrada pela iminência da eclosão da guerra das Malvinas, pairava um clima político de restauração da democracia, e nesse período a revista Hum® "fue catapultada al centro de la escena cultural y mediática, donde desempeñó un papel central para garantizar el retorno al estado de derecho" (BURKART, 2017, p.210). Uma das principais transformações na trajetória de Hum® é que naquele momento de distensão da ditadura, a revista passa a denunciar de maneira explícita atos de censura e violência e a apontar os setores responsáveis das forças armadas, inclusive os pertencentes à alta cúpula militar.

E não foi apenas Hum ${ }^{\circledR}$ que interpretou a chegada do General Roberto Eduardo Viola ao poder em 1981 como uma possibilidade de distensão dos mecanismos repressivos da ditadura militar; novas propostas culturais voltam à cena e outras já existentes ganham maior visibilidade, como o surgimento Teatro Abierto, uma das experiências de resistência cultural contra a ditadura mais importantes da época ${ }^{5}$. Não somente filmes, discos e livros que haviam sido proibidos no início do regime começavam a circular, mas também artistas exilados retornavam e ocupavam a cena, a exemplo do regresso de Mercedes Sosa à Argentina, em 1982, depois de três anos de exílio: apesar das diversas músicas censuradas pelo regime e ameaças de bomba não concretizadas, a cantora lotou as salas do Teatro Ópera, onde realizou treze apresentações ${ }^{6}$. Ou seja, à voz contestatória dos editores e colaboradores de Hum® somavam-se outras vozes.

O livro de Mara Burkart representa uma incursão bem-sucedida na complexidade do estudo do campo do humor gráfico. As revistas tratadas na obra constituem um recurso valioso para refletirmos sobre as possibilidades de abordagem do político a partir de uma perspectiva cultural. Se Hum® permanece presente na memória coletiva da classe média urbana argentina como um dos símbolos de resistência cultural até hoje,

\footnotetext{
5 O movimento Teatro Abierto surge em 1981 como uma experiência de resistência cultural e reação política da classe teatral à ditadura militar. O Teatro Abierto teve um grande poder de influência e inspirou experiências similares por todo o país, tendo extrapolado as fronteiras nacionais e se uniu a outros movimentos de resistência cultural popular no continente. Cf. VILLAGRA, Irene. Teatro Abierto 1981: dictadura y Resistencia Cultural. Estudio Crítico de Fuentes Primarias y Secundarias. Buenos Aires: Ediciones Al Margen, 2013.

${ }^{6}$ Cf. MARCHINI, Dario. No toquen. Músicos populares, gobierno y sociedad. Utopía, persecución y listas negras en la Argentina, 1960-1983. Buenos Aires: Catálogos, 2008.
}

\section{CANPHLAC}

Revista Eletrônica da ANPHLAC, ISSN 1679-1061, №. 25, p. 319-326, Jul./Dez., 2018.

http://revista.anphlac.org.br 
talvez essa seja uma das demonstrações mais consistentes da potencialidade crítica das caricaturas e da força do humor gráfico no campo do político.

\section{Referências bibliográficas:}

ÁGUILA, Gabriela. La dictadura militar argentina: interpretaciones, problemas e debates. Páginas Revista digital de la escuela de historia, Rosario, v. 1, n. 1, 2008. Disponível em: 〈http://revistapaginas.unr.edu.ar/index.php/RevPaginas/article/view/148/148> Acesso em: 20 set. 2017.

BOHOSLAVSKY, Ernesto; FRANCO, Marina; IGLESIAS, Mariana; LVOVICH, Daniel (Orgs.). Problemas de historia reciente del Cono sur. V. 1 e 2. Buenos Aires: UNGS/Prometeo, 2010.

BUCH, Esteban. Música, dictadura, resistencia: la Orquesta de París en Buenos Aires. Buenos Aires: Fondo de Cultura Económica, 2016.

BURKART, Mara. De Satiticón a Hum®: risa, cultura y política en los años setenta. Buenos Aires: Miño y Dávila Editores, 2017.

COSSE, Isabela. Mafalda: história social e política. Buenos Aires: Fondo de Cultura Económica, 2014.

FRANCO, Marina. Un enemigo para la nación: ordem interno, violência y "subversión”, 1973-1976. Buenos Aires: Fondo de cultura Económica, 2012.

LEVÍN, Florencia. Humor político en tiempos de represión. Clarín, 1973-1983. Buenos Aires: Siglo XXI, 2013.

\section{GANPHLAC}


MANZANO, Valeria. contra toda forma de opressor: sexo politica y classes medias juvenil en las revistas de humor de los primeiros 70. Sociohistorica. Cuadernos del CIHS, n. 29, 2012, p. 9-34.

MARCHINI, Dario. No toquen. Músicos populares, gobierno y sociedad. Utopía, persecución y listas negras en la Argentina, 1960-1983. Buenos Aires: Catálogos, 2008.

SLIPAK, Daniela. Las revistas montoneras: como la organización construyó su identidad através de sus publicaciones. Buenos Aires: Siglo XXI, 2015.

VERZERO, Lorena. Teatro militante: radicalización artística y política en los años 70. Buenos Aires: Ed. Biblos, 2013.

VILLAGRA, Irene. Teatro Abierto 1981: dictadura y Resistencia Cultural. Estudio Crítico de Fuentes Primarias y Secundarias. Buenos Aires: Ediciones Al Margen, 2013.

\section{CANPHLAC}

